D.O.I.: $10.3895 /$ gi.v12n4.5217

\title{
ANÁLISE DOS NÍVEIS DE SERVIÇOS ATRAVÉS DA USABILIDADE DO TRANSPORTE PÚBLICO INTERURBANO AQUAVIÁRIO ENTRE OS MUNICÍPIOS RIO DE JANEIRO E NITERÓI
}

\section{ANALYSIS OF SERVICE LEVELS THROUGH THE USABILITY OF AQUAVIAN PUBLIC INTERURBAN TRANSPORT BETWEEN THE RIO DE JANEIRO AND NITERÓI MUNICIPALITIES}

\author{
Gustavo Soares Braga ${ }^{1}$; Roberto Bernardo da Silva ${ }^{2}$; Evaldo Cesar Cavalcante Rodrigues ${ }^{3}$; Priscila \\ Carlos Rosano Peña ${ }^{4}$ \\ ${ }^{1}$ Universidade de Brasília - UnB - Brasília/DF - Brasil \\ gustavobragarj@hotmail.com \\ ${ }^{2}$ Universidade de Brasília - UnB - Brasília/DF - Brasil \\ rbaccioly@gmail.com \\ ${ }^{3}$ Universidade de Brasília - UnB - Brasília/DF - Brasil \\ evaldocesar@unb.br \\ ${ }^{4}$ Universidade de Brasília - UnB - Brasília/DF - Brasil \\ gmcrosano@gmail.com
}

\begin{abstract}
Resumo
O objetivo do presente trabalho é analisar o nível da qualidade dos serviços de mobilidade urbana coletiva oferecida na interligação dos municípios Rio de Janeiro e Niterói através do modal aquaviário, através da identificação dos elementos que fazem diferença para o usuário na usabilidade do sistema. Durante o processo de pesquisa e diagnóstico foram identificados os elementos que fazem diferença para o usuário na usabilidade do referido sistema de transporte que representa uma alternativa ao modal rodoviário, predominante no país. $O$ trabalho consiste nas etapas metodológicas estabelecidas na fase de planejamento e execução da pesquisa, com destaque para: a definição do campo, o objeto estudado, revisão da literatura, definição de critérios, coleta de dados, análise dos dados e informações conclusivas. A pesquisa é teórica e empírica, pois se fundamenta de uma revisão teórica, porém foi feita uma coleta de dados através de questionários aplicados diretamente aos usuários do sistema. O diagnóstico final do sistema constatou que os critérios que mais produzem impacto na percepção do usuário são a sua confiabilidade e seu custo direto, a tarifa, uma vez estabelecidos os padrões mínimos para todos os critérios, estes dois são os que se sobressaem na ótica do usuário e também os que recebem maior rigor no momento de sua avaliação, tal rigor refletiu como o pior desempenho na percepção dos usuários.
\end{abstract}

Palavras-chave: transporte; mobilidade; usabilidade; aquaviário.

\section{Introdução}

A mobilidade urbana trata basicamente da movimentação de pessoas dentro de um ambiente urbano. Todavia a expansão das cidades, a criação espontânea de megalópoles transformou a mobilidade urbana em algo a ser levado com mais seriedade, pois a demanda por 
transporte em um mundo globalizado já rompeu as fronteiras geográficas dos municípios, demandando cada dia mais sistemas que atendam a nova dinâmica urbana das atuais cidades.

O planejamento do sistema de transporte coletivo urbano possui uma gama de variáveis a serem levadas em conta, entre as principais, pode se elencar, questões econômicas, socioambientais, geográficas, além das especificidades da cidade e da população que a habita. Questões ambientais, geográficas e de sustentabilidade já passaram a ser elemento nato de discussões sobre obras de infraestrutura nas cidades, entretanto, nem todo elemento ambiental é necessariamente um obstáculo. O sistema aquaviário pode ser aplicado em locais que a geografia natural da região já permita sem que seja necessário fazer obras de alteração radicais na geografia local.

Entre os dois municípios, ambos situados no estado do Rio de Janeiro, existe um intenso trânsito de pessoas e cargas diariamente, tanto que se fez necessária a construção da ponte Rio Niterói para unir as duas cidades, pois apenas as barcas, já em operação na época de construção, principal meio de transporte direto entre as cidades não eram suficientes para atender ao trânsito pessoas e cargas. Porém com o crescimento populacional e por reflexo também o transito de pessoas, fez com que o transporte aquaviário através da Bahia de Guanabara continuasse a ser uma ótima alternativa na travessia, sendo que nos períodos de pico de trânsito de pessoas, apenas a ponte não atende de forma satisfatória a demanda.

O uso de um modal de transporte alternativo pode ser muito vantajoso econômico e operacionalmente. Dillon (2001) ressalta que a aplicação de um sistema deve considerar como núcleo da análise, não o sistema em si mais o usuário, o que leva ao objeto do estudo deste trabalho, a percepção do nível de serviço das barcas Rio - Niterói pelos usuários. Diante do exposto a pesquisa se propõe a responder a seguinte questão: Qual a percepção do nível de serviço das barcas Rio - Niterói?

O objetivo é analisar a percepção do nível de serviços de mobilidade urbana coletiva oferecida na interligação dos municípios Rio de Janeiro e Niterói através do modal aquaviário, identificando os elementos que fazem diferença para o usuário na usabilidade do sistema de transporte que representa uma alternativa ao modal rodoviário, predominante no país.

O estudo sobre a mobilidade urbana permite buscar melhoria constante tanto para o usuário quanto para um planejamento urbano eficiente permitindo a cada dia o investimento em métodos mais adequados para as novas demandas da sociedade moderna.

\section{Usabilidade}

Segundo a ISO 9241 (2015), parte 11, usabilidade pode ser definida como amplitude de eficácia de um determinado produto, serviço ou sistema tem no alcance de um objetivo definido ao 
ser usado pelo usuário que se dirige em um contexto definido, atendendo aos requisitos de efetividade (capacidade de conclusão do que se propõe), eficiência (conclusão em prazo a contento do usuário) e satisfação (experiência do usuário).

Cybis, Betiol e Faust (2010) definem que a usabilidade pode ser tomada como o aspecto qualificador do uso de um sistema cuja operação se dá de forma interativa entre o usuário e o sistema através da interface, analisando sua eficiência e eficácia.

Usando as definições de Nielsen (1993), podemos definir que usabilidade não pode ser compreendida como uma perspectiva unidimensional, abarcando pelo menos cinco critérios de avaliação:

- Capacidade de aprendizado: a facilidade com que o usuário tem de, ao primeiro contato, aprender a usar o sistema e concluir o objetivo definido.

- Eficiência: o nível de eficiência que o sistema tem após o momento que o usuário aprende a utilizá-lo.

- Capacidade de memorização: o sistema de deve ser simples ou ponto que um usuário que já esteja familiarizado com ele não tenha dificuldade de usar após um lapso de tempo sem o ter usado.

- Nível de erros e nível de correção: aqui temos dois aspectos entrelaçados, pois um sistema deve possuir uma baixa taxa de erros durante o uso e os erros que acontecerem devem ser corrigíveis, erros incorrigíveis e de difícil restauração não devem existir.

- Satisfação: um conceito extremamente subjetivo, porém muito importante qualquer que seja o sistema, ele deve agradar o usuário de modo que ele fique satisfeito ao usá-lo e não lhe cause aversão.

Como dito por Shackel (1991) muitos sistemas são criados tendo suas partes operacionais como o centro de atenção colocando o usuário como coadjuvante no processo, porém o desempenho do sistema vai depender fundamentalmente da experiência do usuário na utilização, sua eficiência e sua eficácia serão medidas a partir do usuário e não do sistema, compreendendo isso e transpondo esses conceitos para os sistemas de transporte público podemos compreender que o planejamento de desses sistemas deve, antes de compreender e planejar o sistema, compreender as demandas do usuário.

O conceito cunhado por Dillon (2001) diz que a usabilidade é uma medida de qualidade da interface que se refere à eficácia, eficiência e satisfação com que os usuários podem executar tarefas com uma ferramenta. Pode-se contextualizar esses conceitos no objeto de estudo que é o transporte 
público, com foco no modal aquaviário, como o nível de facilidade de uso, acessibilidade, eficiência, eficácia e nível de incidentes que esse transporte permite, avaliando a satisfação do usuário sob a ótica desses prismas, de modo algum supondo que tais avaliações esgotem as possíveis perspectivas e critérios verificáveis.

\section{Transporte Público e Mobilidade Urbana}

O transporte de pessoas e cargas faz parte da história do ser humano desde antes das palavras "transporte" e "logística" serem cunhadas e vem sendo aprimorado ao longo da história na medida em que a demanda por seu desenvolvimento assim exige. No Brasil a Constituição Federal de 1988 define como competência do Estado, exercida pelos municípios a responsabilidade organizar e prestar, diretamente ou sob-regime de concessão ou permissão, os serviços públicos de interesse local, incluído o de transporte coletivo, que tem caráter essencial.

Como citato por Rodrigues (2014) o crescimento demográfico acelerado, acompanhado pelo êxodo rural em vários países fez com que a quantidade de veículos particulares transitando nos centros metropolitanos aumentar de modo que houve uma necessidade de se repensar o transporte público coletivo.

Molinero e Arellano (2005) estabelecem um conceito diferenciando o transporte público e o privado, sendo o transporte privado em geral operado pelo dono, se deslocando por vias criadas e mantidas pelo poder público, o transporte público é operado pelo governo ou a quem ele autorize mediante contratação especifica e utilizado para a movimentação de massas.

Vuchic (2007), Molinero e Arellano (2005) afirmam que transporte público urbano pode ser definido como transporte de pessoas operado em horário e rota fixos, tendo acesso a ele qualquer pessoa mediante tarifa prefixada, ressalta-se quem já existem previsões legais em determinados países de isenção de tarifa de grupos específicos (estudantes, professores, idosos, etc.),

Vuchic (2007) enfatiza que grandes cidades e áreas metropolitanas são centros de diversas atividades, que requerem um sistema de transporte, de pessoas e bens, eficiente e conveniente, o trânsito nas grandes vias de uma cidade se compara ao sangue sendo bombeado dando vida à cidade, a alta densidade de atividade e de pessoas torna possível e necessário o desenvolvimento de meios de alta capacidade de transporte coletivo de pessoas, modais que usam menos energia e espaço que meios particulares de condução que em grande maioria são carros de pequeno porte com capacidade de levar no máximo cinco passageiros, limitado a pessoas quem tem poder aquisitivo e habilitação para poder guiar esses veículos. 
A problemática quanto ao meio de transporte aplicado ao transporte coletivo público deve levar em conta fatores geográficos, pois a discussão de implantação de um sistema ferroviário pode tornar a obra economicamente inviável dependendo da distância, fazendo com que talvez um sistema rodoviário seja o mais indicado assim como um sistema aquaviário deve antes verificar se haverá demanda para o mesmo e se as hidrovias por onde ele será implantado podem suportar aquele tipo de embarcação.

\section{Modais de Transporte}

Existem basicamente cinco modais de transporte; rodoviário, ferroviário, aquaviário, dutoviário e aéreo, esses últimos dois ficaram de fora da discussão por não realizar transporte de pessoas e por não se enquadrar no objeto de pesquisa deste trabalho (transporte coletivo público) respectivamente. Segundo Guimarães e Junior (2015) a escolha do modal está ligada a relação custo-benefício, nesse conceito se contempla custo socioambiental e custo financeiro, uma vez que cada modal apresenta diferentes características e possibilidades de resultados distintos em cada aspecto.

Sempre que são feitas considerações e comparações entre modais é preciso avaliar a finalidade a que se propõe, Nazário (2000) define cinco características que podem ser interrelacionadas entre os modais e assim, ranqueadas, são elas: velocidade, disponibilidade, confiabilidade, capacidade e frequência; o quadro 2.1 traz essa correlação ranqueando cada modal com os números de 1 a 5, sendo o número 1 o melhor ranqueado naquela característica e o número 5, o pior, a escolha do modal deve levar em conta o que é prioridade para atividade que se deseja executar.

Quadro 4.1: Características Operacionais.

\begin{tabular}{llllll}
\hline Características & Ferroviário & Rodoviária & Aquaviário & Dutoviário & Aereoviário \\
\hline Velocidade & 3 & 2 & 4 & 5 & 1 \\
\hline Disponibilidade & 2 & 1 & 4 & 5 & 3 \\
\hline Confiabilidade & 3 & 2 & 4 & 1 & 5 \\
\hline Capacidade & 2 & 3 & 1 & 5 & 4 \\
\hline Frequência & 4 & 2 & 5 & 1 & 3 \\
\hline Resultado & $\mathbf{1 4}$ & $\mathbf{1 0}$ & $\mathbf{1 8}$ & $\mathbf{1 7}$ & $\mathbf{1 6}$
\end{tabular}

O modal aquaviário, objeto de pesquisa deste trabalho, possui várias peculiaridade, pois sua implantação tem um elevado custo e depende preponderantemente de fatores geográficos, quando se trata de mobilidade urbana elementos como a relação custo-benefício e viabilidade socioambiental e econômica são avaliados de forma meticulosa, segundo Ribeiro (2012) as principais vantagens do modal aquaviário são, a alta capacidade de transporte, a possibilidade de transporte simultâneo de passageiros e carga, e o valor de transporte que é consideravelmente mais 
baixo do que os outros modais, Martinez e Negenborn (2015) ressalta que o que o modal aquaviário depende de outros modais pois cada localidade possui especificidade que impõem demandas diferenciadas e uma região metropolitana exige uma interligação eficiente entre seus meios de transporte.

\section{Transporte Aquaviário}

O uso de meio de transporte aquaviário remonta a antiguidade, desde o período dos faraós o Nilo era o canal de transporte de pessoas e cargas, a evolução tecnológica desse meio de transporte permitiu viagens cada vez mais distantes e explorações cada vez mais audaciosas, permitindo a descoberta de novos continentes e uma revolução significativa na possibilidade de transporte de grandes quantidades de pessoas e cargas de um ponto a outro.

Segundo o Ministério dos Transportes (2015), o transporte aquaviário, aquático ou hidroviário pode ser definido como todo transporte de cargas ou passageiros por barcos, navios ou balsas que transitem através de hidrovias (percursos pré-determinados para tráfego de embarcações), podendo ser rios, canais, lagos, bacias ou mar aberto.

No Brasil, é a Constituição Federal de 1988 já determinou, nos art. 21, 22 e 23 onde define as competências da União que a ela compete explorar e legislar matéria pertinente a transporte aquaviário e aos Municípios compete à organização e a prestação de serviços de transporte coletivo público uma vez que possuem caráter essencial como já mencionado.

Schneider (2000) enfatiza que o modal aquaviário possui uma gama de vantagens em relação às desvantagens, pois após sua implantação, tem um custo menor de manutenção e um custo marginal baixo por passageiro, o impacto ambiental também é menor pois não exige modificações topográficas da região se utilizando em muitas das vezes dos recursos naturais na forma como estão (lagos, rios, bacias, etc.), possui também uma emissão de poluentes menor se comparada à quantidade de passageiros que a embarcação possui, a principal desvantagem é o alto custo de implantação.

Segundo Martinez e Negenborn (2015) o sistema de transporte público aquaviário além de ser economicamente atrativo e viável pois usa os recursos naturais da localidade deve possuir integração com os demais sistemas de transporte para que o trânsito de pessoas seja eficiente e ofereça um bom nível de serviço. 


\section{Métodos e técnicas de pesquisa}

O trabalho seguiu as etapas estabelecidas na fase de planejamento, respectivamente: definição do campo, do objeto e do aspecto a ser estudado, revisão da literatura, plano de pesquisa, definição de critérios, coleta de dados, análise dos dados e publicação.

$\mathrm{Na}$ fase de revisão da literatura, o estudo traz uma análise especifica dividida em quatro categorias: Usabilidade, Transporte Público e Mobilidade Urbana, Modais de Transporte e Transporte Aquaviário. Foram levados em consideração artigos publicados em congressos e periódicos nacionais e internacionais e livros de diversos autores que se focavam no tema, também incluíram dissertações e teses acadêmicas de mestrado e doutorado, respectivamente. A última fase de revisão da literatura foi focada na pesquisa documental de publicações oficiais, verificando a disponibilidade de dados fornecidos por documentos eletrônicos oficiais, decretos governamentais, endereços eletrônicos de órgãos oficiais, empresas e governos.

O modelo de análise multicritério de apoio à decisão (MCDA-C - Construtivista Método: Multicriteria Decision Aid Constructivist) foi o modelo escolhido para a pesquisa.

A aplicação do método MCDA-C seguiu respectivamente as seguintes fases, identificar rótulo e possíveis atores da pesquisa, definição dos atores com participação ativa na pesquisa, propor elementos de avaliação, brainstorming e pontos de vista, construção dos decisores, estruturação do instrumento de coleta de dados, tabulação dos dados coletados e publicação.

Por uma questão logística financeira não foi viável a reunião com decisores do sistema, foram então substituídos por especialistas em transporte que possuem vasto conhecimento no campo para dar suporte à construção do questionário.

A coleta de dados foi feita em ambos os terminais dos dois municípios, realizada através de questionários, com escala de impacto indo de 1 a 5 , onde 1 corresponde a nenhum impacto e 5 a impacto altamente perceptível, a fim de avaliar a percepção do usuário dos elementos que de fato são fundamentais na análise de usabilidade.

Por fim, o tratamento dos dados foi feito através do software de modelagem MAMADecisão, desenvolvido no Programa de Pós-Graduação em Transportes (PPGT) da Universidade de Brasília - UnB.

\subsection{Tipo e descrição geral da pesquisa}

A abordagem é tanto qualitativa quanto quantitativa, pois foi realizada a quantificação das respostas dos usuários, estabelecendo critérios objetivos com escalas de percepção e níveis de impacto sob essa percepção, também a modelagem dos dados utilizada através do software 
MAMADecisão que é uma ferramenta de análise de impacto e níveis de esforços que dá assim um caráter quantitativo à pesquisa, ao mesmo tempo, a abordagem é qualitativa pois faz uma análise de percepção de qualidade sob um aspecto subjetivo individual percebido pelo usuário.

A pesquisa é teórica e empírica pois se fundamenta numa revisão teórica, porém, foi feita uma coleta de dados através de questionários aplicados diretamente aos usuários do sistema. $\mathrm{O}$ delineamento da pesquisa é preponderantemente descritivo embora haja correlação entre variáveis estabelecidas entre dos decisores e especialistas consultados.

O método da pesquisa adotado foi o estudo de caso, com a análise do estudo em profundidade do caso específico, subordinando a pesquisa ao contexto, às características e à história do objeto estudado.

\subsection{Caracterização da organização}

O sistema de transporte aquaviário entre as cidades do Rio de Janeiro e Niterói existe desde 1835. O Transporte de passageiros e cargas entre as cidades era explorado por uma empresa privada, após o golpe militar de 64 o Governo Federal decidiu então estatizar a então empresa privada a transformando em empresa pública e a ser denominada STBG - Serviços de Transportes da Baia de Guanabara, que em 1977 foi doada pelo Governo Federal ao Estado do Rio de Janeiro com a transformação para a então CONERJ - Companhia de Navegação do Estado do Rio de Janeiro.

Em 1998 um consórcio de empresas privadas assumiu o controle acionário da Companhia de Navegação do Estado do Rio de Janeiro (CONERJ), sob o regime de concessão, dando origem a Barcas S/A.

Entre 2006 e 2009 os investimentos em inovações e melhorias permitiu a inauguração de quatro catamarãs sociais, as embarcações que possuem dupla proa, eliminaram a necessidade de manobra e reduziram o tempo de viagem na linha Rio - Niterói para 20 minutos, com capacidade para 1.300 passageiros (900 sentados e 400 em pé). A empresa conta com uma frota variada que realiza outras linhas, atualmente a concessionária realiza seis linhas fixas ligando oito destinos. Em 2012, 80\% do capital do capital da empresa foi comprado pelo grupo CCR, sendo nesse mesmo ano o nome da empresa foi mudado para CCR Barcas.

\subsection{População e amostra}

A composição deste estudo é feita na população de ambos os municípios, como o estudo foi qualitativo e quantitativo na percepção dos usuários do sistema de transporte não se identificou uma necessidade de estabelecer critérios de identificação de cada população, tendo em vista que 
ambas utilizam o mesmo sistema e o foco do estudo não é comparativo. De acordo com Barcas S.A. - Transportes Marítimos (2015), a concessionária transporta diariamente cerca 110 mil passageiros em todo o sistema. Por ano, navega aproximadamente 640 mil quilômetros, transportando cerca de 29 milhões de passageiros, em mais de 80 mil viagens. Salienta-se que o número apresentado foi publicado no Diário Oficial do Estado do Rio de Janeiro no RELATÓRIO DA ADMINISTRAÇÃO da concessionária no dia cinco de março de 2015.

A finalidade da amostragem é produzir um subconjunto representativo da população. $\mathrm{O}$ objetivo da amostragem aleatória é que se consiga representar no todo o que se constada na amostra sendo definida por meios estatísticos, o modelo empregado foi de amostra aleatória simples. Amostra aleatória simples é aquela na qual todos os elementos têm a mesma probabilidade de serem selecionados. Nessa pesquisa foi coletado 36 questionários com o objetivo de subsidiar o trabalho na análise da percepção do usuário.

\subsection{Estruturação do MACD-C}

O MACD-C (Método de Análise Multicritério para Apoio a Decisão) é uma ferramenta dedicada a encontrar múltiplos pontos ótimos, auxiliando na tomada de decisão. Uma vez definido o elemento de estudo, é utilizada uma metodologia construtivista que visa elaborar um mecanismo que possa avaliar os elementos que produzem impacto na percepção do indivíduo foco do estudo. No mundo pós-segunda guerra o uso de pesquisa operacional foi altamente empregado para auxiliar as tomadas de decisões, assim sendo, vários modelos foram surgindo.

Com os avanços no campo foi se percebendo que análise unidimensional não era suficiente para dar suporte seguro à tomada de decisão. Nesse âmbito fez necessária a análise dos atores que interagem no ambiente de estudo, nessa concepção a ferramenta de análise multicritério para apoio a decisão gerencial é denominada Multicriteria Decision Aid Constructivist (MCDA-C)

\subsection{Rótulo e Atores da Pesquisa}

Nesta fase foi estabelecido o rótulo que norteou a escolha dos elementos de avaliação a serem levados em conta (A percepção da qualidade do nível de serviço no transporte público através de barcas no trajeto Rio - Niterói na percepção do usuário).

Por questões de distância e financeiras, se tornou inviável a realização de Brainsstorming com os decisores internos da empresa pesquisada (CCR - Barcas), sendo assim, foram substituídos por especialistas, profissionais de notório saber dos sistemas de transporte público. Recaindo ao pesquisador, que conduziu a pesquisa, a função de moderador, por último ressalta-se a importância dos usuários que tiveram sua colaboração através de questionários. 


\subsection{Elementos Primários de Avaliação}

Após as etapas iniciais, identificam-se os Elementos Primários de Avaliação (EPAs), foi utilizada, como ferramenta para chegar a uma congruência de conhecimentos afins, o Brainsstorming, reunindo em um mesmo ambiente, especialistas no setor que colaboraram para validar a definição dos Elementos Primários de Avaliação (EPAs) e a fim de estabelecer os critérios a serem avaliados (SubEPAs 1), e seus subcritérios (SubEPAs 2) bases que formaram as questões, e seus devidos pesos (ou taxas de substituição).

Os especialistas escolhidos para a realização do Brainsstorming foram membros do Grupo de pesquisa em Planejamento e Inovação em Transportes - GPIT do Programa de Pós-graduação em Transportes - PPGT / UnB. O Quadro 6.1 apresenta os critérios (EPAs) avaliados, e no que consiste cada um deles.

Quadro 6.1 - Elementos Primários de Avaliação do Sistema de Interligação dos municípios Rio - Niterói por hidrovias.

\begin{tabular}{|l|l|}
\hline Critério & Conceito \\
\hline Confiabilidade & $\begin{array}{l}\text { Capacidade de o sistema de transporte público cumprir o itinerário diário dentro do previsto e } \\
\text { ser capaz de lidar com possíveis contratempos ao ponto de não gerar transtorno aos } \\
\text { passageiros }\end{array}$ \\
\hline $\begin{array}{l}\text { Viagem e tempo de } \\
\text { deslocamento }\end{array}$ & $\begin{array}{l}\text { Qualidade durante a viagem, tempo de duração do deslocamento e trancos na saída e na } \\
\text { chegada. }\end{array}$ \\
\hline Acessibilidade & $\begin{array}{l}\text { Acessibilidade para portadores de necessidades especiais, eliminação de barreiras, agilidade e } \\
\text { facilidade para PNE }\end{array}$ \\
\hline Conforto & $\begin{array}{l}\text { Conforto nas salas de embarque e nas embarcações (qualidade dos assentos, banheiros, } \\
\text { terminais de energia, iluminação, etc.) }\end{array}$ \\
\hline Conveniência & $\begin{array}{l}\text { Facilidade de na compra do bilhete e embarque, lojas e lanchonetes, acessos a pontos de } \\
\text { energia, proximidade de terminais de outros modais, }\end{array}$ \\
\hline Segurança & $\begin{array}{l}\text { Atender as demandas dos conceitos "security" e "secure", ou seja, fornece uma viagem } \\
\text { segura e que tenha também segurança. }\end{array}$ \\
\hline Custo (tarifas) & Preço dos bilhetes vendidos, grupos de tarifa reduzida. \\
\hline
\end{tabular}

\subsection{Construção dos Descritores}

No Brainsstorming foram analisados os Elementos Primários de Avaliação para desenvolver os critérios, subcritérios e base para questões e seus respectivos pesos (taxas de substituição), a partir dos julgamentos dos representantes (especialistas). Na Tabela 6.2 tanto os Elementos Primários de Avaliação quanto suas subclasses possuem uma valoração de participação estabelecida em porcentagem (\%) cuja soma dos elementos individuais soma $100 \%$ na sua classe como descrito por Rodrigues (2014). 
Tabela 6.2 - Tabela de EPA's, SubEPA's 1 e SubEPA's 2

\begin{tabular}{|c|c|c|}
\hline EPA'S & SubEPA`s 1 & Sub EPA`s 2 \\
\hline \multirow{6}{*}{ 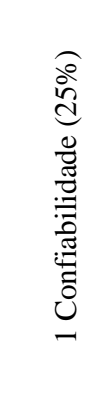 } & \multirow{3}{*}{$\begin{array}{l}\text { 1.1 Pontualidade no } \\
\text { cumprimento da tabela de } \\
\text { horários }(50 \%)\end{array}$} & $\begin{array}{l}\text { 1.1.1 Coerência entre o tempo planejado e o real de saída do ponto inicial do itinerário } \\
(30 \%)\end{array}$ \\
\hline & & $\begin{array}{l}\text { 1.1.2 Coerência entre o tempo planejado e o real de chegada do ponto final do itinerário } \\
(30 \%)\end{array}$ \\
\hline & & 1.1.3 Tempo de espera $(40 \%)$ \\
\hline & \multirow{3}{*}{$\begin{array}{l}1.2 \text { Regularidade dos } \\
\text { intervalos para as linhas } \\
(50 \%)\end{array}$} & 1.2.1 Quantidade de veículos/hora em horários de pico (40\%) \\
\hline & & 1.2.2 Quantidade de veículos/hora em horários de entre-pico (40\%) \\
\hline & & 1.2.3 Quantidade de veículos/hora durante os finais de semana e feriados (20\%) \\
\hline \multirow{11}{*}{ 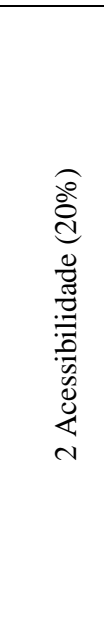 } & \multirow{3}{*}{$\begin{array}{l}2.1 \text { Facilitação para } \\
\text { Portador de Necessidades } \\
\text { Especiais }- \text { ambiente } \\
\text { interno e externo }(20 \%)\end{array}$} & $\begin{array}{l}\text { 2.1.1 Opções acessibilidade para PNE`s (rampas, avisos sonoros, elevadores...) } \\
(33,3 \%)\end{array}$ \\
\hline & & 2.1.2 Banheiros para PNE $(33,3 \%)$ \\
\hline & & 2.1.3 Facilitação no embarque e desembarque $(33,3 \%)$ \\
\hline & \multirow{2}{*}{$\begin{array}{l}2.2 \text { Ambiente externo } \\
(30 \%)\end{array}$} & 2.2.1 Indicação sobre os terminais com símbolos e letreiros $(60 \%)$ \\
\hline & & 2.2.2 Indicação dos terminais em suas proximidades (40\%) \\
\hline & \multirow{4}{*}{$\begin{array}{l}2.3 \\
(30 \%)\end{array}$ Ambiente interno } & 2.3.1 Informações sobre horário e itinerários nos terminais (30\%) \\
\hline & & 2.3.2 Informações sobre integração nos terminais (35\%) \\
\hline & & $\begin{array}{l}\text { 2.3.3 Informações prévias sobre mudanças no funcionamento do sistema nos terminais } \\
(25 \%)\end{array}$ \\
\hline & & 2.3.4 Profissionais disponíveis para atendimento a dúvidas (10\%) \\
\hline & \multirow{2}{*}{$\begin{array}{l}2.4 \text { Sistema de bilhetagem } \\
(20 \%)\end{array}$} & 2.4.1 Informações sobre formas de pagamento (40\%) \\
\hline & & 2.4.2 Compra e recarga de bilhetes $(60 \%)$ \\
\hline \multirow{12}{*}{$\begin{array}{l}\text { of } \\
0 \\
0 \\
o \\
0 \\
0 \\
0 \\
0 \\
m \\
m\end{array}$} & \multirow{2}{*}{3.1 Operação $(30 \%)$} & 3.1.1 Manobra e condução do veiculo (60\%) \\
\hline & & 3.1.2 Estabilidade da embarcação (40\%) \\
\hline & \multirow{5}{*}{$\begin{array}{l}3.2 \quad \text { Condições } \\
\text { Embarcações }(40 \%)\end{array}$} & 3.2.1 Quantidade de assentos disponíveis (30\%) \\
\hline & & 3.2.2 Climatização (20\%) \\
\hline & & 3.2.3 Limpeza (10\%) \\
\hline & & 3.2.4 Qualidade dos assentos (20\%) \\
\hline & & 3.2.5 Poluição (sonora, visual, ar, ...) (20\%) \\
\hline & \multirow{5}{*}{$\begin{array}{l}3.3 \quad \text { Estrutura dos } \\
\text { Terminais }(30 \%)\end{array}$} & 3.3.1 Quantidade de assentos (30\%) \\
\hline & & 3.3.2 Condições de manutenção do local (20\%) \\
\hline & & 3.3.3 "quiosques" para lanches rápidos (12\%) \\
\hline & & 3.3.4 Banheiros (quantidade e estado de conservação) (25\%) \\
\hline & & 3.3.5 Serviços de apoio (Pontos de energia, telefones públicos ...) (13\%) \\
\hline \multirow{6}{*}{ 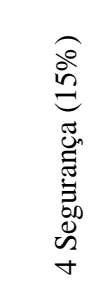 } & \multirow{3}{*}{ 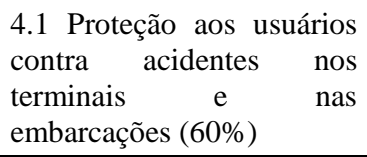 } & 4.1.1 Condução segura da embarcação (25\%) \\
\hline & & 4.1.2 Presença de quantidades suficientes de coletes salva-vidas (50\%) \\
\hline & & 4.1.3 Orientações quanto ao uso dos EPI`s (25\%) \\
\hline & \multirow{3}{*}{$\begin{array}{l}\text { 4.2 Proteção aos usuários } \\
\text { contra crimes nos terminais } \\
\text { e nas embarcações }(40 \%)\end{array}$} & 4.2.1 Presença de profissionais de segurança $(35 \%)$ \\
\hline & & 4.2.2 infraestrutura de segurança (câmeras, catracas...) (35\%) \\
\hline & & 4.2.3 Informativos quanto ao nível de segurança oferecido ao usuário (30\%) \\
\hline \multirow{5}{*}{ 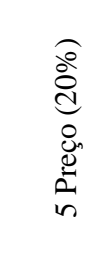 } & \multirow{2}{*}{5.1 Valor $(80 \%)$} & 5.1.1 Gasto mensal em relação ao salário mensal do usuário (70\%) \\
\hline & & 5.1.2 Custo x Benefício (30\%) \\
\hline & \multirow{3}{*}{$\begin{array}{l}5.2 \quad \text { Transparência e } \\
\text { Política }(20 \%)\end{array}$} & 5.2.1 Políticas de gratuidade e desconto $(35 \%)$ \\
\hline & & 5.2.2 Informações sobre possibilidades e opções de bilhetes (35\%) \\
\hline & & 5.2.3 Informações sobre os valores e composição das tarifas (30\%) \\
\hline
\end{tabular}

Fonte: Elaboração Própria, 2016. 
No fim do processo de construção foram definidos 40 dos descritores que serviram de base para a construção das questões do formulário. Relacionando cada descritor com o conjunto de níveis de impacto, foi construído um questionário, que foi aplicado nos terminais para 36 usuários. O Quadro 6.3 traz uma seção do questionário onde o usuário foi solicitado assinalar a opção mais apropriada na sua percepção: (1) Péssimo ou Ruim, (2) Sem Opinião ou Indiferente, (3) Regular, (4) Bom ou boa e (5) Excelente.

Quadro 6.3 Exemplo de seção do questionário.

\begin{tabular}{|c|c|c|c|c|c|c|}
\hline Item & Pontos sobre o Qualidade Percebida & 1 & 2 & 3 & 4 & 5 \\
\hline \multirow{7}{*}{ 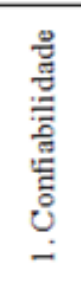 } & 1.1.1. Cumprimento dos horánios de saida dositineránios & & & & & \\
\hline & 1.1.2. Cumprimento dos horános de chegada ao final dositineránios & & & & & \\
\hline & 1.1.3. Tempo de espera no teminal/ponto/estação & & & & & \\
\hline & 1.1.4. Tempo de viagem & & & & & \\
\hline & 1.2.1. Quantidade de veiculos para atender a população nos horános de pico (mais movimento) & & & & & \\
\hline & 1.2.2. Quantida de de veículos para atender a população nos horánios de menor movimento & & & & & \\
\hline & 1.2.3. Quantidade de veículos para atender a população nos finais de semana e feriados & & & & & \\
\hline
\end{tabular}

Fonte: Elaboração Própria, 2016.

\section{Análise do Nível de Serviços do Transporte Público Interurbano Aquaviário}

Os dados foram analisados e verificada a performance demonstrada por cada descritor percebida pelos usuários, os descritores, como mostrado na tabela 6.2 estão agrupados em cinco grandes grupos, os Elementos Primários de Avaliação.

O nível UsabBrcMax apresenta o melhor desempenho potencial de cada descritor, o nível UsabBrcMin o menor desempenho potencial e o UsabBrc é o desempenho real identificado, a amplitude entre o nível máximo e o mínimo apresenta qual a quantidade de esforço que cada descritor demanda para alterar sua atual posição, compreenda-se que todo esforço empregado pela empresa pode ser traduzido como recursos, sejam eles financeiros, de logística ou de qualquer outra natureza, quanto menor o intervalo entre o nível mínimo e o máximo significa que o caminho a ser percorrido é menor, ou seu investimento para alcançar o resultado ótimo para a empresa será menor.

\subsection{Confiabilidade}

A confiabilidade esta ligada a eficiência e eficácia do sistema, um dos elementos abordados por Nielsen em sua explanação sobre a usabilidade, tais elementos tem valor preponderante para o usuário, pois além do sistema ser capaz de cumprir sua finalidade, precisa executar tal tarefa no horário programado, no gráfico 7.1 pode ser visto o desempenho da confiabilidade do sistema. 
Gráfico 7.1, Confiabilidade.

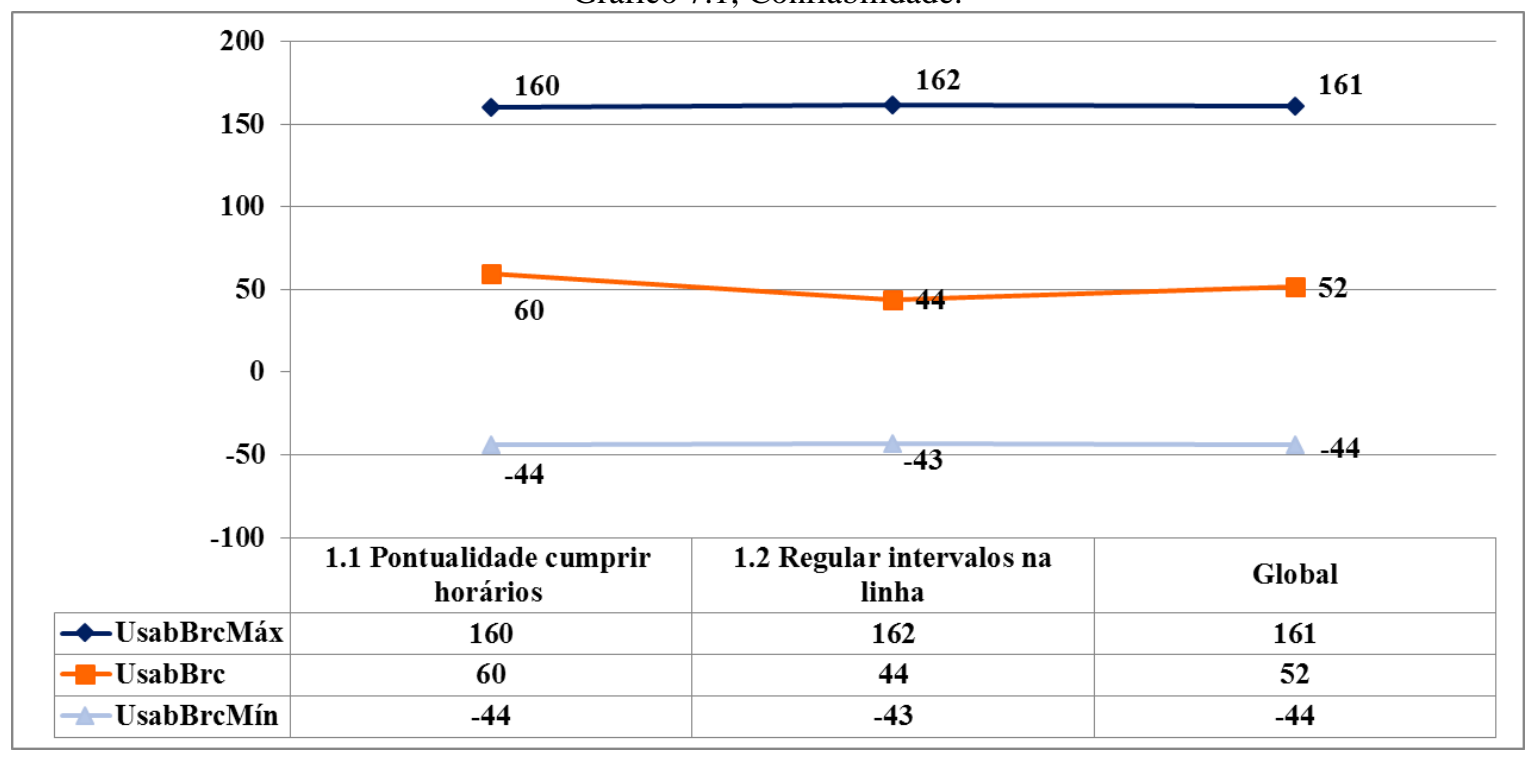

Fonte: Elaboração Própria, 2016.

Como pode ser verificado, ambos os itens que compoem o indicador de confiabilidade tem uma aplitude semelhante, seus potenciais máximos e minímos tem uma uma aplitute praticamente idêntica, apresentando apenas 1 ponto para cima de diferença, feita as devidas correções, essa igualdade aproximada indica que os níveis de esforços para implementar melhorias em ambos os itens são semelhantes.

O resultado real identificado apresenta um desempenho inferior no quesito de regularidade entre as linhas, impactando na confiabilidade do sistema, quando se trata de mobilidade urbana a regularidade do sistema colabora para a rotina do ambiente urbano ao que se propõe atender, a não regularidade do atendimento impede que o usuário tenha uma previsibilidade programável de uso das barcas.

Como ferramenta de auxílio na tomada de decisão, a análise multicritério permite uma visão mais abrangente das variáveis e suas relações, nesse caso específico não existe um comportamento diverso entre cada item, pois ambos apresentam um comportamento semelhante, é recomendável que nesse caso se invista no indicador que apresenta o menor desempenho para igualar ambos indicadores pelo melhor.

\subsection{Acessibilidade}

A acessibilidade nesse estudo possui mais de uma esfera, pois é analizado o nível de acessibilidade de portadores de necessidades especiais, como cadeirantes, deficientes visuais, auditivos ou pessoas com dificuldade de locomoção causada por algum motivo, porém também são verificados elementos de acessibilidade que alcançam todos os usuários de forma homogênea, 
elementos que permitem o fácil acesso ao sistema das barcas desde as proximidades para se chegar à estação até após o desembarque, no gráfico 7.2 pode ser visto a performance real constatada os níveis de esforços de transição do desempenho mínimo ao máximo.

Gráfico 7.2, Acessibilidade.

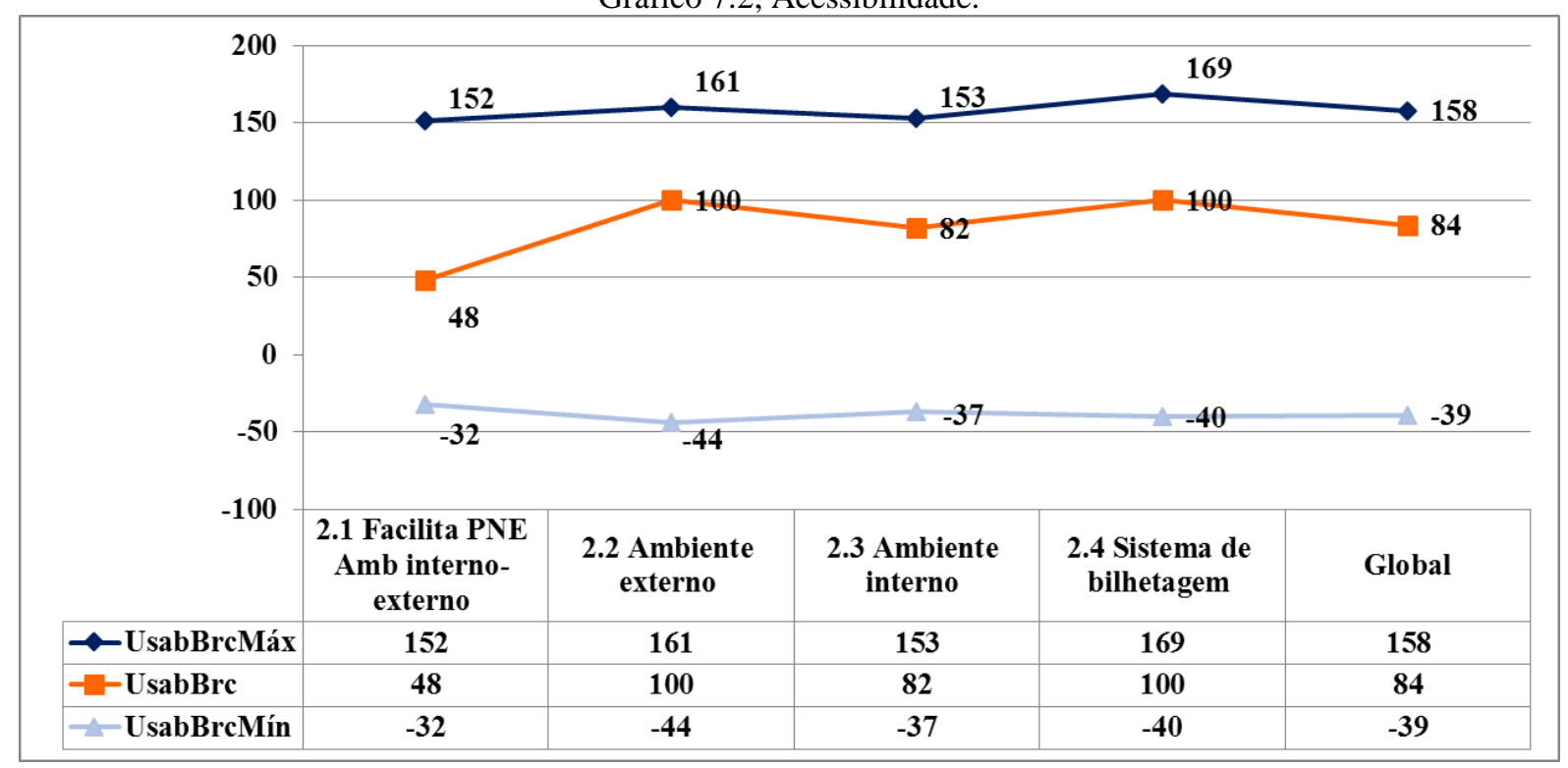

Fonte: Elaboração Própria, 2016.

O gráfico acima demonstra que a amplitude dos níveis de esforços dos elementos de acessibilidade que são pertinentes a todos os passageiros apresenta uma maior amplitude, demonstrando que melhorias voltadas a todos os usuários demandam mais esforços, o item 2.1 que avalia a percepção do usuário na acessibilidade de portadores de necessidade especiais tem uma menor amplitude, indicando que investimentos feitos neles terão um impacto maior que nos outros elementos, ou que melhorias nesses elementos demandam menos recursos para alcançar melhorias perceptíveis para o usuário e uma melhora no desempenho final do elemento "Acessibilidade".

A pesquisa demonstrou que, em contra ponto ao fato de ser o elemento que demanda menor esforço para alcançar níveis perceptíveis de melhora, a percepção quanto à acessibilidade a portadores de necessidade especiais foi a pior entre todas, indicando que o gestor que tiver o objetivo de melhorar a acessibilidade na percepção dos usuários deverá ter como ponto de partida esse elemento, pois é o que demandara menor esforço e produzirá o resultado mais impactante para o valor global da acessibilidade do sistema tendo em vista outros indicadores já possuem desempenhos superiores.

\subsection{Conforto}

O conforto é um conceito subjetivo, pois cada usuário pode ter um conceito e uma percepção diferentes, comparações com outros sistemas semelhantes e com o sistema anterior podem influenciar no julgamento, para avaliar elementos com esses níveis de subjetividade é preferível uma coleta maior possível, para ter uma visão geral da percepção dos usuários, outra 
ferramenta utilizada é a separação de indicadores e avaliação de cada um e de seu nível de impacto no critério a ser avaliado, no quadro abaixo é possível identificar os resultados e a comparação dos esforços de cada elemento avaliado.

Gráfico 7.3, Conforto.

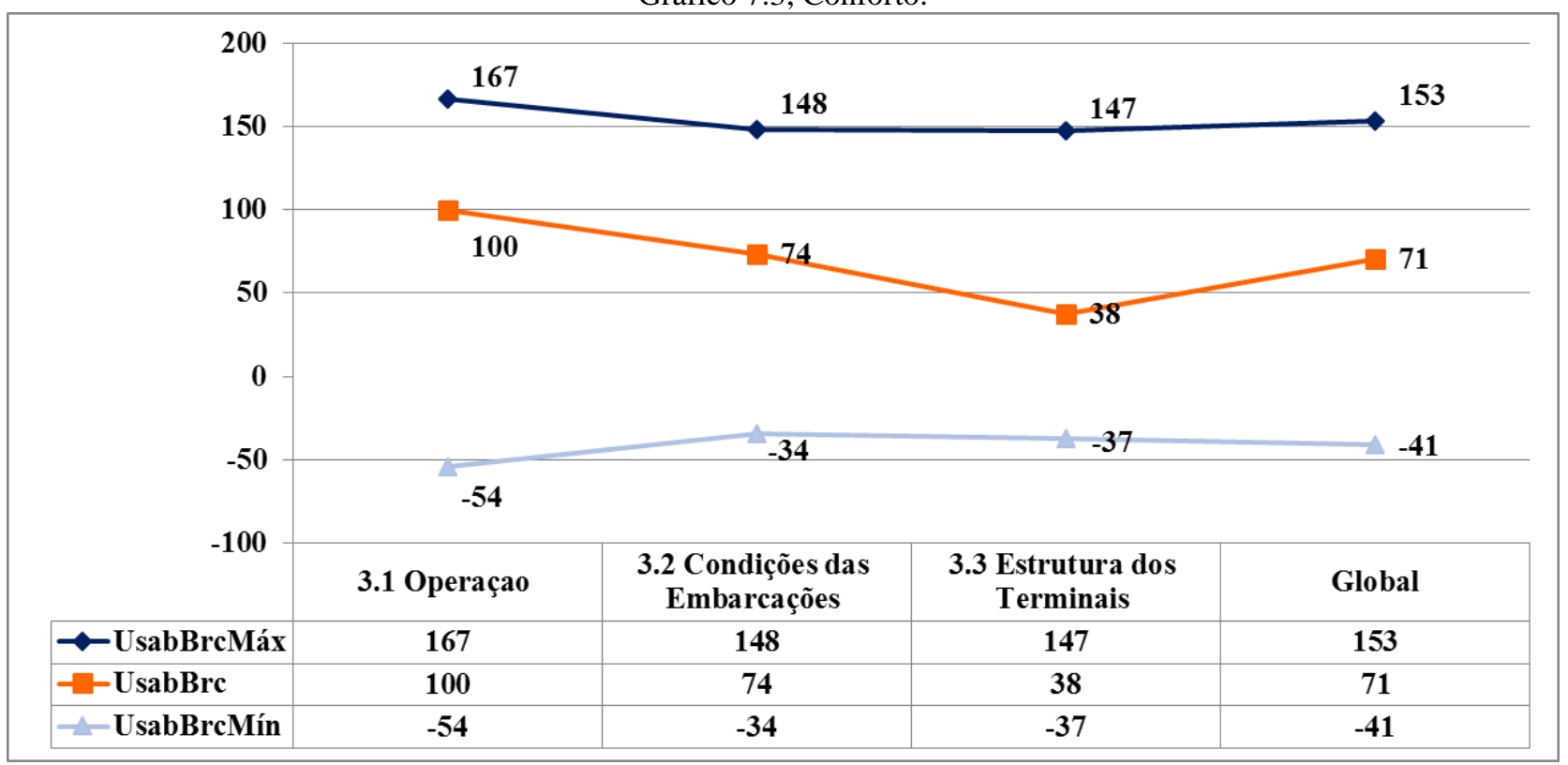

Fonte: Elaboração Própria, 2016.

O criterio de conforto foi composto de três sub critérios, como o Gráfico 7.3 mostra, as condições das embarcações e a estrutura dos terminais tem uma amplitude semelhante indicando que ambos têm níveis de esforcos semelhantes enquanto o a operação das embarcações apresenta um desafio maior já que o intervalo entre o minimo e o maximo resultado é maior, indicando que para se alcancar o resultado maximo o volume de investimentos de ser maior.

O resultado real apresentado da percepção dos usuários mostra que embora o item 3.1 seja o que tem o maior distância em entre seus extremos, também é o que teve o melhor desempenho, enquanto o item 3.3 Estrutura dos terminais teve o pior desempenho. No momento da tomada de decisão, o item que já apresenta um bom desempenho pode ser tratado em um momento mais oportuno, o item que demanda menos investimentos para se alcançar um resultado ótimo e no momento é o que está apresentando a pior performance deve priorizado.

\subsection{Segurança}

O conceito de seguranca pode ser decomposto basicamente em duas esferas, é comum o uso da nomeclatura em língua inglesa "secure and security", pois a primeira remete a segurança operacional e contra incidentes não intencionais, a segunda faz referência a segurança contra atos de ordem criminosa ou terrorista, em que há intenção de causar dano, este estudo decompôs esses conceitos e verificou não sua eficiência ou sua eficácia nas barcas e nos terminais, porém sim a 
percepção de cada um deles pelos usuários que utilizao o sistema de transporte na travessia da Bahia de Guanabara.

Gráfico 7.4, Segurança.

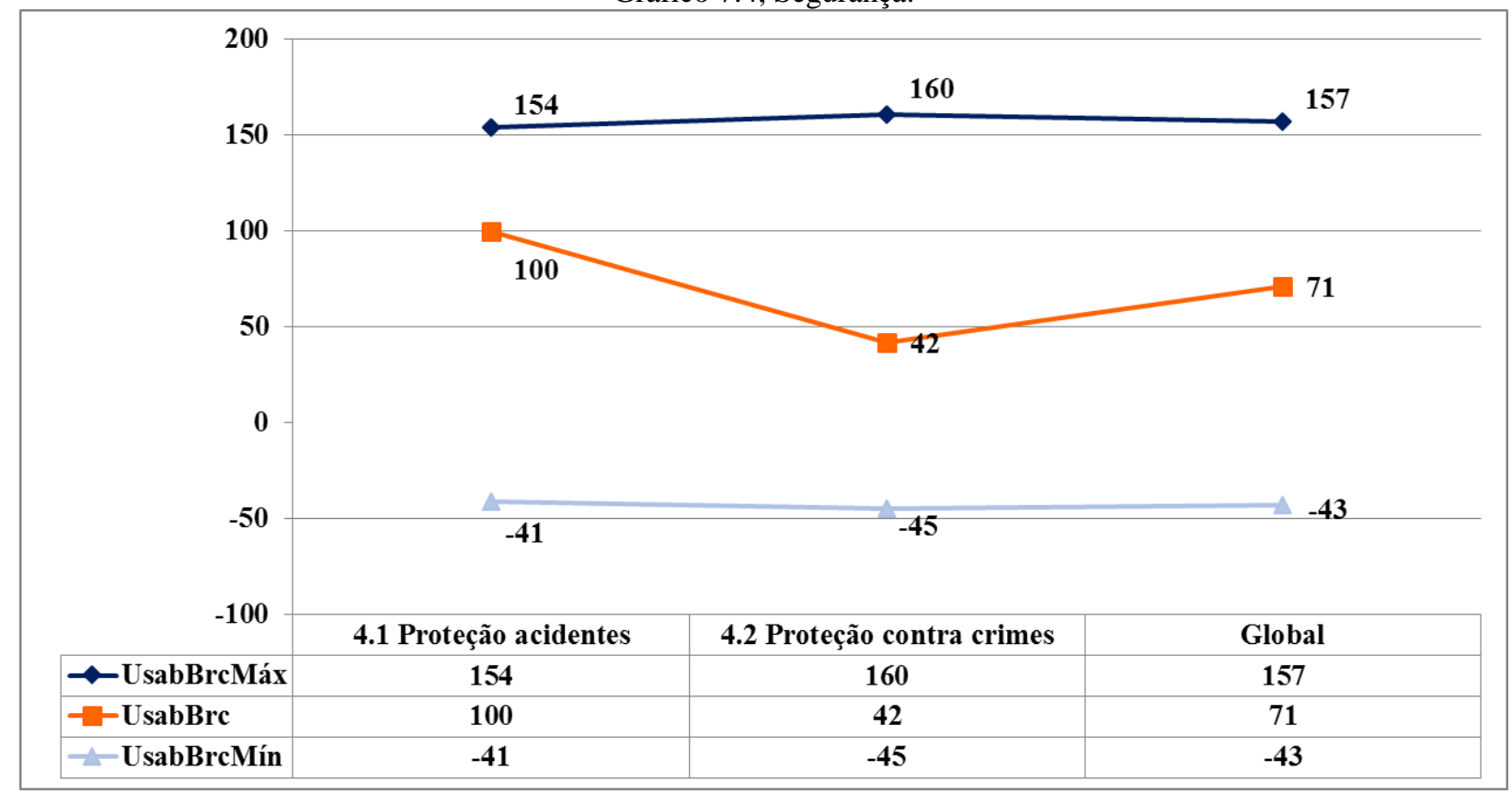

Fonte: Elaboração Própria, 2016.

O Gráfico 7.4 que mostra a performance dos critérios e dos sub critérios de avaliação da percepção dos usuarios quanto aos níveis de seguranca oferecido aos nos terminais e nas embarcações, como pode ser visto itens não apresentam uma diferenca muito forte em seus potenciais extremos indicando que amabas as esferas supracitadas demandam recursos em proporções semelhantes.

O desempenho dos descritores demonstrou uma percepção relativamente negativa quanto à percepção dos níveis de segurança contra incidentes de ordem criminosa, demonstrando que investimentos nessa área devem ser priorizados, sejam eles de ordem operacional de fato, ou na sua demonstração, passando aos usuários a conscientização do nível de segurança oferecido em todo o sistema.

\subsection{Tarifa}

O valor cobrado pela passagem é sem duvida um dos maiores desafios para a empresa já questões de ordem externa exercem influência, por se tratar de uma concessionária que firmou um contrato com o governo ela se torna parceira do governo e o estabelecimento da tarifa não é uma decisão tomada apenas dentro da empresa, mas depende de interesses externos, conciliar tais questões é tarefa complexa. 
Além disso a composição da tarifa possui vários fatores como tributos e subsídios que o usuário não tem, na maioria das vezes, consciência do que de fato está pagando, basicamente o usuário demanda preços mais acessíveis e deseja serviços de qualidade, no gráfico 7.5 a percepção do usuário quanto à relação Custo x Beneficio foi verificada assim como a transparência quanto à composição da tarifa.

Gráfico 7.5, Tarifa.

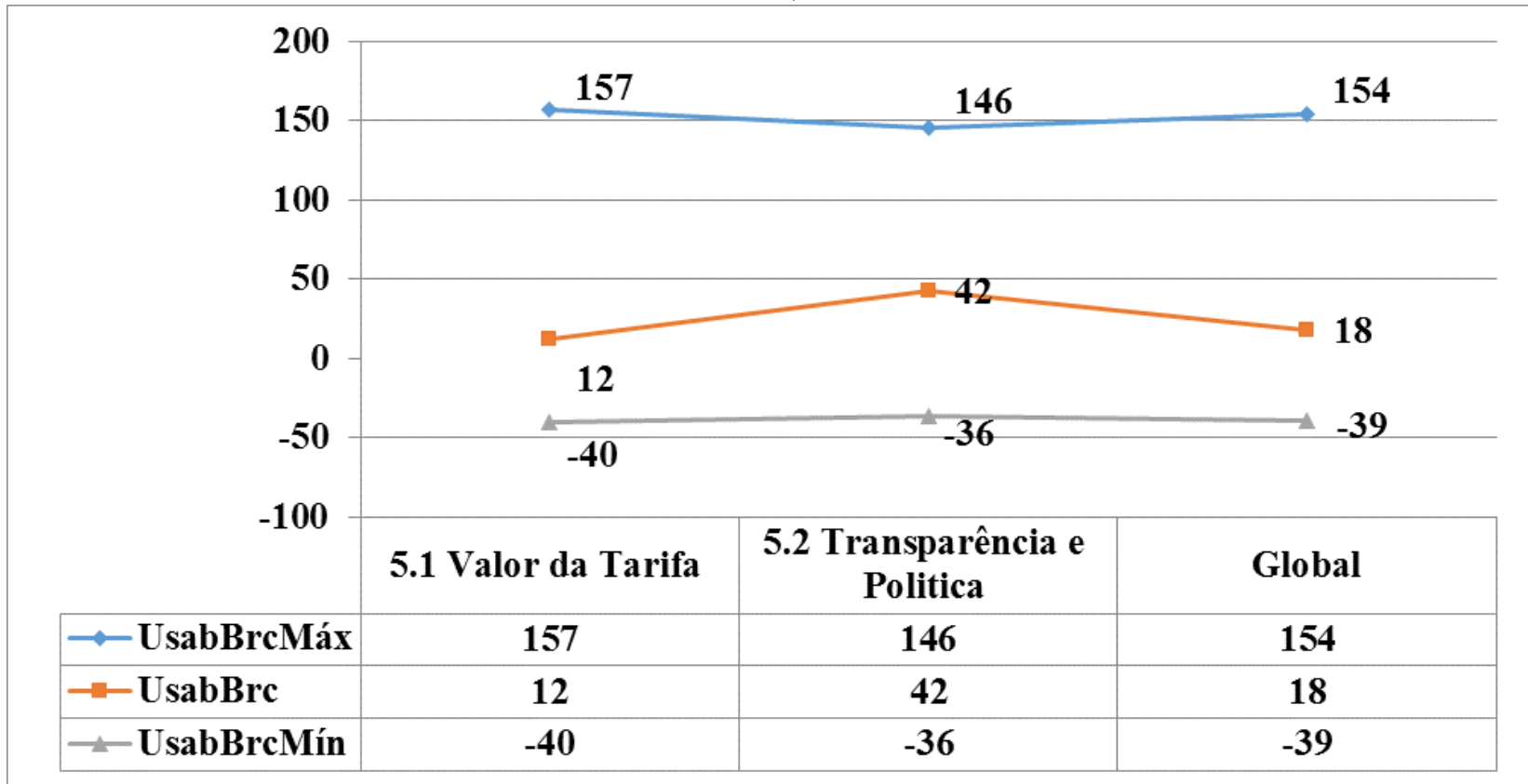

Fonte: Elaboração Própria, 2016.

Como pode ser visto no gráfico 7.5 pode ser comprovado que o maior desafio resite no valor da tarifa, apresentando uma distância maior entre seus extremos do que o item que trata de transparência na composição da tarifa e políticas que influenciam.

A atual percepção dos usuários mostra um desempenho negativo do indicador que refere ao valor da tarifa, estando mais próximo de seu extremo mínimo indicando que o critério que demanda mais esforço é também o que apresenta o pior desempenho, reforçando a necessidade de maior atenção do gestor para encontrar alternativas para realizar incrementos nesse critério.

\subsection{Resultado Global}

O gráfico 7.6 abaixo apresenta os resultados globais de todos os critérios de forma comparativa entre eles e apresentando os potenciais máximos, mínimos e o resultado real constatado, e seus intervalos de esforços, com o objetivo de identificação de quais são os maiores desafios para a melhoria das barcas. 
Gráfico 7.6, Resultado Global.

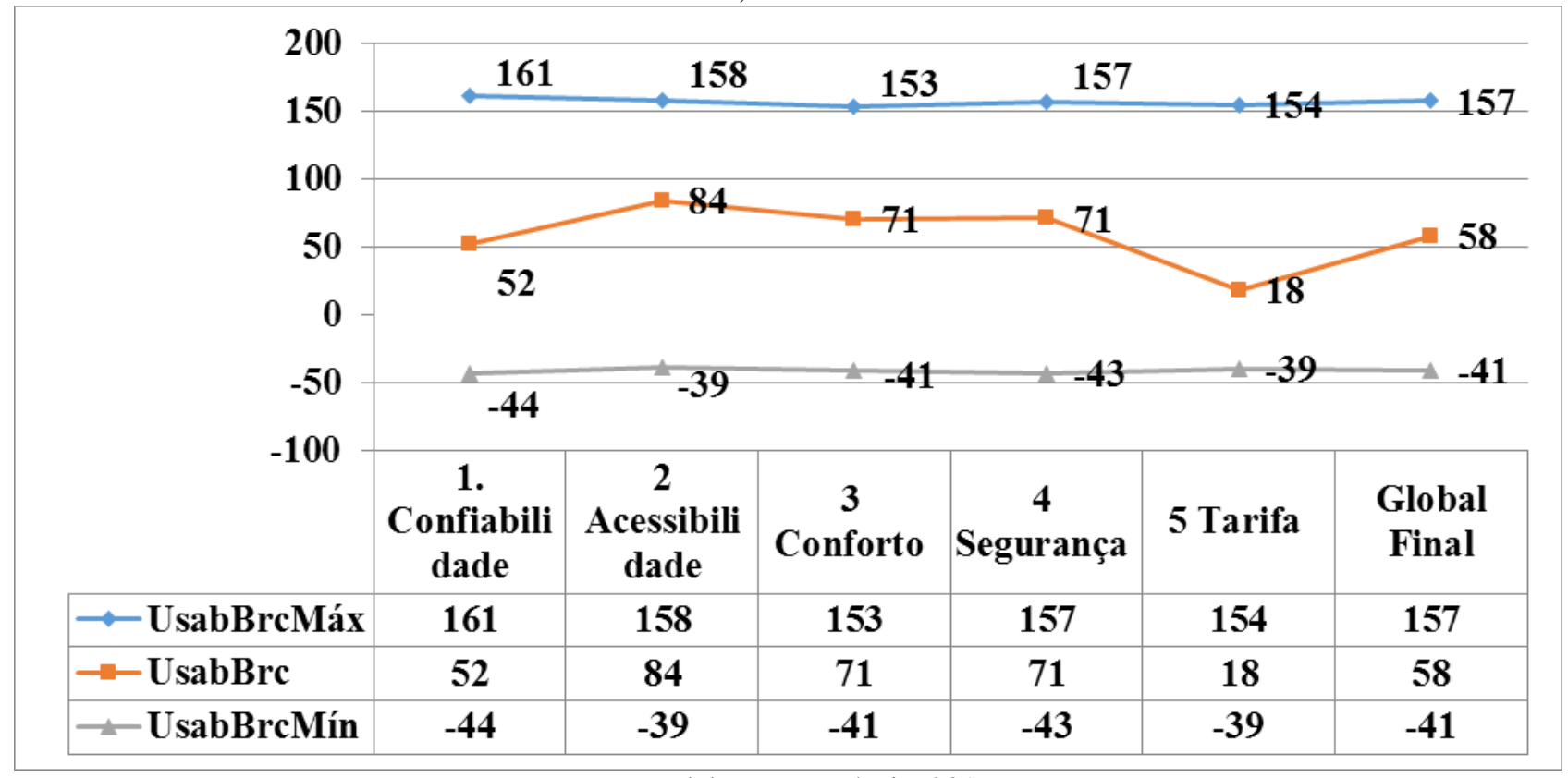

Fonte: Elaboração Própria, 2016.

Como é possível ver, não houve uma discrepância muito grande entre os extremos de cada um dos cinco elementos avaliados na percepção dos usuários, demonstrando certa proximidade nos níveis de esforços, investimentos iguais em cada critério produzirá uma alavancagem semelhante, todos os elementos demandam quantidades semelhantes de recursos para produzirem melhoras com amplitudes semelhantes.

Tendo essa percepção de níveis de esforços em cada elemento, pode se passar a uma análise comparativa de desempenho real constatado, no gráfico acima é possível constatar que os elementos 1. Confiabilidade e 5. Tarifa foram os que apresentaram os piores desempenhos, os outros elementos tiveram a performance relativamente melhor, ainda que exista um hiato entre o desempenho real e o ótimo, os itens que começam a lista e a terminam demandam mais atenção e investimentos se o objetivo dos tomadores de decisão tiverem como meta uma melhora dos pontos fracos na ótica do usuário.

\section{Conclusões}

Ao analisar a usabilidade de transporte público interurbano aquaviário oferecido na interligação entre os Municípios do Rio de Janeiro e Niterói, foram identificados os elementos que geram diferenciais de qualidade para o usuário do sistema de transporte, que representa uma relevante alternativa ao modal rodoviário predominante no país.

Através de todo o processo foi possível identificar e estabelecer os elementos que são relevantes para a análise do sistema de transporte analisado, estabelecer graus de impacto que cada elemento tem sob a percepção do usuário. 
A análise dos itens derivados da decomposição do conceito de usabilidade permitiu a identificação de quais pontos demandam atenção por estarem abaixo da expectativa do gestor e quais estão dentro do esperado. A análise multicriterial permitiu a identificação de esforços e a relação comparativa de cada critério analisado, permitindo ao gestor avaliar quais investimentos devem se feitos para produzir o maior impacto positivo para o usuário com o menor recurso possível. O investimento em melhorias constantes e o norteamento para futuros investimentos no setor podem ser pautados nos fatores estabelecidos por este estudo.

\begin{abstract}
The objective of the present work is to analyze the level of quality of collective urban mobility services offered in the interconnection of Rio de Janeiro and Niterói municipalities through waterway modalities, through the identification of the elements that make difference to the user in the usability of the system. During the research and diagnosis process, the elements that make a difference to the user in the usability of said transportation system were identified, which represents an alternative to the road modal, predominant in the country. The work consists of the methodological steps established in the planning and execution phase of the research, highlighting: the definition of the field, the object studied, literature review, definition of criteria, data collection, data analysis and conclusive information. The research is theoretical and empirical, since it is based on a theoretical review, but a data collection was done through questionnaires applied directly to the users of the system. The final diagnosis of the system found that the criteria that most impact the perception of the user are their reliability and their direct cost, the tariff, once the minimum standards for all the criteria have been established, these are the ones that stand out from the perspective of the Users and also those that are more rigorous at the time of their evaluation, such rigor reflected as the worse performance in the perception of the users.
\end{abstract}

Keywords: transport; mobility; usability; waterway.

\title{
Referências
}

CYBIS, Walter; HOLTZ, A.; FAUST, Richard. Ergonomia e usabilidade. São Paulo: Novatec, 2010.

Dillon, A. (2001) Usability evaluation. In W. Kïarwowski (ed.) Encyclopedia of Human Factors and Ergonomics, London: Taylor and Francis.

DO RIO DE JANEIRO, Diário Oficial Do Estado. Rio de Janeiro, RJ, (DOERJ) de 05 de Março de 2015, Pág. 8.

Disponível em: http://www.jusbrasil.com.br/diarios/87181089/doerj-publicações -a-pedido-05-03-2015-pg-8/pdfView acesso em: 26 de abril de 2016.

FEDERAL, Senado. Constituição da república federativa do Brasil. Brasília: Senado, 1988.

Disponível em: http://www.planalto.gov.br/ccivil_03/constituição/ConstituiçãoCompilado.htm Acesso em 20 de março de 2016

GUIMARÃES, Vanessa A.; JUNIOR, Ilton Curty Leal. AVALIAÇÃo DO DESEMPENHO DOS MODOS DE TRANSPORTE URBANO DE PASSAGEIRO COM BASE NA SUSTENTABILIDADE. ANAIS: XXIX ANPET Ouro Preto - MG 2015. 4 p

ISO/DIS 9241-11(en) Ergonomics of human-system interaction - Part 11: Usability: Definitions and concepts 2th Ed. (2015)

Disponível em: https:/www.iso.org/obp/ui/\#iso:std:iso:9241:-11:dis:ed-2:v1:en Acesso em 11 de março de 2016.

MINISTÉRIO DOS TRANSPORTES, 2016. Disponível em http://www.transportes.gov.br http://www.transportes.gov.br/transporte-rodoviario-relevancia.html http://www.transportes.gov.br/transporteferroviario-relevancia.html http://www.transportes.gov.br/transporte-aquaviario-relevancia.html Acesso em 28 de março de 2016. 
MOLINERO, ARM; ARELLANO, LIS. Transporte público: planeación, diseño, operación y administración, $1^{\mathrm{a}}$ reimpresión. UAEM, Toluca, 2005.

NIELSEN, Jakob. Usability engineering. Elsevier, 1994[p 23-43]

OCAMPO-MARTINEZ, Carlos; NEGENBORN, R. Transport of Water versus Transport over Water. Springer International Publishing, 2015

RIBEIRO, Roberto Portes; PACHECO, Fernando Fachin. Custo do transporte aquaviário do arroz beneficiado na região centro RS até São Luis-MA.Anais: XXXII ENEGEP, 2012.

RODRIGUES, E. C. C. (2014). Metodologia para investigação da percepção das inovações na Usabilidade do sistema metroviário - uma abordagem antropotecnológica. Tese de doutorado em Transportes, Publicação T. D. 006A / 2014, Departamento de Engenharia Civil e Ambiental, Universidade de Brasília, Brasília, DF, 262 p.

SHACKEL, B. Usability - context, framework, design and evaluation. In Shackel, B. and Richardson, S. (Eds.). Human Factors for Informatics Usability. Cambridge University Press, Cambridge, 21-37. 1991.

SCHNEIDER, N. C. B. G. Hidrovias interiores: um modal econômico e ambientalmente viável. 2000. Tese de Doutorado. Dissertação (Mestrado em Gestão Econômica do Meio Ambiente), Universidade de Brasília.

VUCHIC, Vukan R. Urban transit systems and technology. John Wiley \& Sons, 2007.

\section{Dados dos Autores}

Nome completo: Gustavo Soares Braga

Filiação Institucional: Universidade de Brasília

Departamento: Administração

Função ou cargo ocupado: Graduado

Endereço completo para correspondência: Quadra 2, Conjunto C15, Bloco B, Apartamento 206, Sobradinho-DF

CEP 73.015-315

Telefone para contato: (61) 98550-2538

E-mail: gustavobragarj@hotmail.com

Nome completo: Evaldo Cesar Cavalcante Rodrigues

Filiação Institucional: Universidade de Brasília

Departamento: de Administração - FACE

Função ou cargo ocupado: Professor Efetivo

Endereço completo para correspondência: Campus Darcy Ribeiro - Prédio da FACE - Asa Norte

- Brasília - DF - CEP: 70910-900

Telefone para contato: (61) 99300-6008

E-mail:evaldocesar@unb.br 
Nome completo: Roberto Bernardo da Silva

Filiação Institucional: Universidade de Brasília

Departamento: Engenharia Civil e Ambiental - Programa de Pós-graduação em Transportes

Função ou cargo ocupado: Doutorando

Endereço completo para correspondência: Campus Universitário Darcy Ribeiro - Prédio SG 12 da FT - Brasília-DF | CEP 70910-900

Telefone para contato: (61) 98130-8586

E-mail: rbaccioly@gmail.com

\section{Nome completo: Carlos Rosano Peña}

Filiação Institucional: Universidade de Brasília

Departamento: Administração

Função ou cargo ocupado: Professor Adjunto

Endereço completo para correspondência: Campus Darcy Ribeiro - Prédio da FACE - Asa Norte

- Brasília - DF - CEP: 70910-900

Telefone para contato: (62) 99299-9917

E-mail: gmcrosano@gmail.com

Submetido em: 15-12-2016

Aceito em: $31 / 12 / 2016$ 